\title{
Oral health and nutritional biochemical variables in adult patients with AIDS
}

\author{
N. Slobodianik ${ }^{1}$, P. Perris ${ }^{1}$, A. Squassi ${ }^{2,3}$, G. Sánchez ${ }^{2,3}$, M. S. Feliu ${ }^{1}$ and N. Bordoni ${ }^{3}$ \\ ${ }^{1}$ Department of Nutrition, School of Pharmacy and Biochemistry, ${ }^{2}$ Oral Care Clinic for High Risk Patients (CLAPAR I) \\ and ${ }^{3}$ School of Dentistry, University of Buenos Aires, Argentina
}

High prevalence of oral disease has been observed in patients with $\operatorname{AIDS}^{(1-3)}$. The aim of this preliminary study was to analyse oral health and its relationship with nutritional biochemical variables in a group of adult patients with AIDS. Twenty-eight patients between 25 and 50 years old who were HIV + were included. Dental status, gingival status and presence of mucosal alterations were determined. The DMFT index (decayed, missed and filled teeth) and its components (gingival index, bleeding sites and the presence of erosion on soft tissues) were calculated and evaluated ${ }^{(4)}$. Samples of whole blood and non-stimulated saliva were collected from fasting patients and serum transthyretin (TTR), C3c fraction (C3c) and total saliva IgA levels were determined by quantitative radial immunodiffusion on layers (The Binding Site, Birmingham, UK and Diffuplate; Biocientifica, Buenos Aires, Argentina) ${ }^{(5-7)}$. The results were (mg/l): IgA 82 (SD 41); TTR 271 (SD 177); C3c 828 (SD 380). When results were compared with reference values (227 (SD 74), 337 (SD 92 ) and 1350 (SD 270) respectively) a reduction in levels was observed. Moreover, also observed were: (a) a negative correlation between the D component of DMFT and the number of bleeding sites and TTR levels $(r-0.68, P<0.001)$; (b) a positive correlation between the presence of lesions on soft tissues and the concentration of total IgA in saliva $(r 0.84, P<0.001)$. No correlation between gingival index and biochemical variables was observed. The results suggest a compromised nutritional status concomitant with alterations in oral health in the study group.
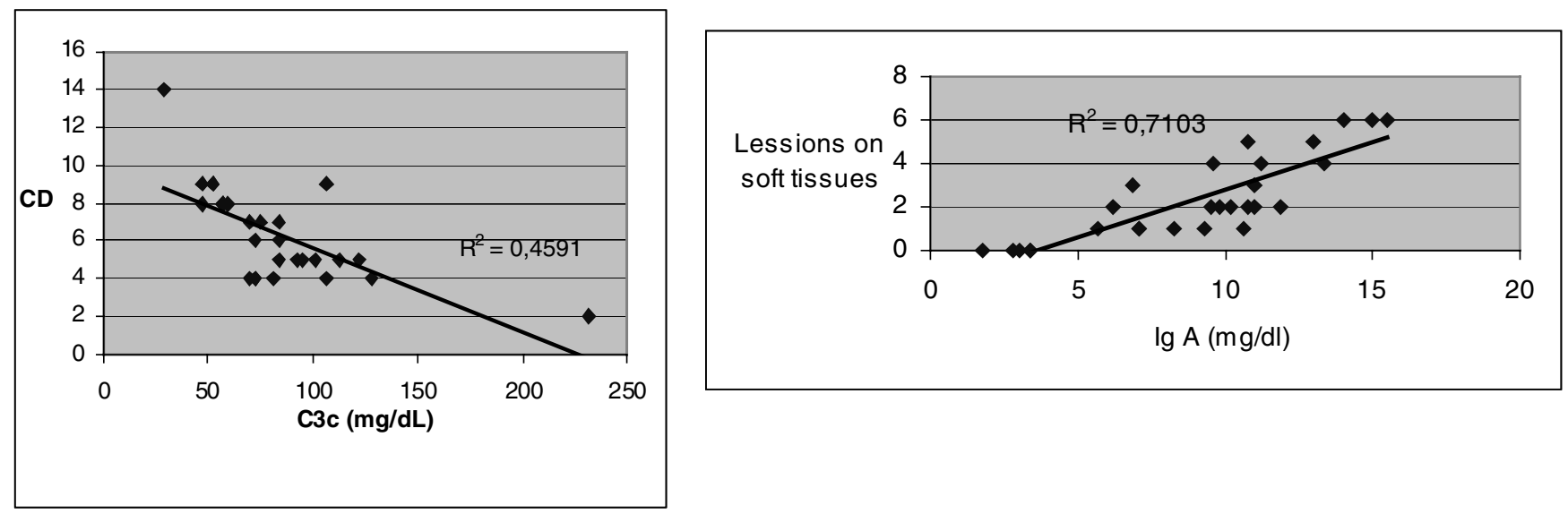

This work was partially supported by the University of Buenos Aires (Grants B060 and O750).

1. MacPhail LA \& Greenspan JS (1997) Oral Dis 3, Suppl. 1, S190-S193.

2. Aguirre-Urizar JM, Echebarria-Goicouria MA \& Eguia del Valle A (2004) Med Oral Patol Oral Cir Bucal 9, Suppl., 148-157.

3. Fidel PL (2006) Adv Dent Res 19, 80-84.

4. Loe H (1967) J Periodontol 38, 610-618.

5. Mancini G, Carbonara AO \& Heremans GF (1965) Immunochemistry 2, 235-254.

6. Feliu MS \& Slobodianik N (1993) Acta Bioquim Clin Latinoam xxvii, 519-526.

7. Slobodianik N \& Feliu MS (1992) Acta Bioquim Clin Latinoam xxvi, 101-102. 